\title{
Analisa Kognitif Model Blended Learning Dengan Pendekatan Kalkulus Dasar
}

\author{
Sumihar Simangunsong ${ }^{1}$, Ika Trisna ${ }^{2}$ \\ ${ }^{1}$ Teknik Geologi,Institut Sains dan Teknologi TD.Pardede, Indonesia \\ ${ }^{2}$ Pendidikan Fisika, Universitas Darma Agung, Indonesia \\ *Email: sumiharbwv79@yahoo.co.id
}

\author{
Received: 3 April 2021; $\quad$ Accepted: 4 Mei 2021; \\ Published: 29 Mei 2021 \\ DOI: http://dx.doi.org/10.29303/jpft.v7i1.2580
}

\begin{abstract}
Abstact - This research was motivated by the low learning outcomes of students in basic physics courses. This is due to the learning of basic physics which requires mathematical analysis in interpreting and analyzing the variables of physical quantities. The purpose of this study was to see the increase in learning outcomes as a result of the application of the blended learning model with the basic calculus approach. This approach is used because basic calculus can analyze basic physical substances through differential and integral languages. The sample of this research was students majoring in mining ISTP Medan. The research method used was a Quasi-experimental one group design. To see the learning outcomes, a learning outcome test is used and a gain test is used to improve learning outcomes. The results showed that the gain test at the first meeting was 0.6, the second meeting was 0.6 and the third meeting was 0.7 with the high category. From research result there is an increase in the gain for each meeting, it is concluded that there is an increase in student learning outcomes as a result of the blended learning model with the basic calculus approach.
\end{abstract}

Keywords: Cognitive; Blended Learning; Basic Calculus

\section{PENDAHULUAN}

Penelitian Pembelajaran fisika saat ini banyak dilakukan dikarenakan sistem pembelajaran disekolah-sekolah banyak mengalami perkembangan yang ditandai dengan perkembangan teknologi yang sangat pesat. Perkembangan teknologi yang masuk kedunia pendidikan formal telah memicu adanya strategi pembelajaran yang lebih dapat mengakomodasi banyak informasi ilmu pengetahuan dan teknologi. Sistem yang lebih tepat bukan lagi kepada satu sistem yang konvensional (tatap muka dikelas) tetapi harus didukung kepada strategi pembelajaran modern yakni melalui literasi dari internet. Sehingga perbaikan dalam kegiatan pembelajaran perlu dilakukan agar kemampuan peserta didik dalam menganalisa (berpikir kritis) dapat meningkat (Hidayatullah et al., 2018).

Perkembangan teknologi informasi sangat membawa dampak positif bagi dunia pendidikan. Tersedianya informasi yang melimpah membuat buku cetak bukan lagi satu satunya sumber ilmu pengetahuan bagi peserta didik. Sudah barang tentu pengguna teknologi informasi harus dapat menggunakannya secara benar karna jika tidak digunakan secara tepat hal ini dapat membawa dampak negatif terhadap pengguna khususnya dan masyarakat umumnya. Penggunaan teknologi dalam pendidikan dapat meningkatkan pemahaman konsep serta analisis (Nisrina et al., 2017). Daya dorong keaktifan siswa pun dapat ditingkatkan karna hal ini memicu keaktifan siswa tersebut dalam menggunakan teknologi tersebut (Konopka, 2015).

Blended learning adalah model pembelajaran yang mendorong keaktifan siswa dalam mengumpulkan informasi berupa ilmu tersebut. Model blended learning adalah model yang mengk ombinasikan pembelajaran konvensional dengan pembelajaran e-learning. Dimana pembelajaran ini tidak lagi dibatasi ruang 
dan waktu karna pembelajaran dapat dilakukan melalui jarak jauh yang dalam hal ini menggabungkan pembelajaran sinkron dan pembelajaran asinkron. Siswa dapat belajar dimanapun dan kapanpun dengan banyak sumber media. Blended Learning telah mendorong penggunaan sumber sumber ilmu yang luas. Maka dari itu baik guru dan dosen telah dipacu untuk mencapai pemahaman dan analisis yang baik terhadap apa yang dipelajari.

Blended Learning juga dapat dilakukan meLalui pendekatan saintifik karna dilakukan dengan pembelajaran asinkron dimana tersedianya konten materi digital, baik berupa e-book, animasi, simulasi, dan bentuk lainnya yang dapat diakses secara online.

Struktur kognitif adalah suatu tingkatan penguasaan dari pemahaman, analisis maupun kreasi dari seseorang. Secara khusus Bloom mengurutkan taksonomi kognititf dari level terendah ke level tertinggi menjadi tujuh level mulai dari mengingat, memahami, menerapkan, menganalisa, mengevaluasi serta mencipta. Meningkatkan kognitif tersebut tidak terlepas dari bagaimana mengoptimalkan proses-proses kognitif. Profil proses kognitif ditampilkan pada table 1 .

Tabel 1. Profil Proses Kognitif

\begin{tabular}{lll}
\hline No & Profil Kognitif & Definisi \\
\hline 1 & Interpretasi, & $\begin{array}{l}\text { Mengubah dari } \\
\text { bentuk yang satu ke } \\
\text { bentuk yang lain. } \\
\text { Menemukan contoh } \\
\text { khusus atau ilustrasi } \\
\text { dari suatu konsep } \\
\text { atau prinsip. }\end{array}$ \\
2 & Mencontohkan, & $\begin{array}{l}\text { Menentukan sesuatu } \\
\text { yang dimiliki oleh } \\
\end{array}$ \\
& & Mengklasifikasikan kategori. \\
& & $\begin{array}{l}\text { Pengabstrakan tema- } \\
\text { tema umum atau } \\
\text { poin-poin utama. } \\
\text { Penggambaran } \\
\text { kesimpulan logis }\end{array}$ \\
\hline
\end{tabular}

\begin{tabular}{lll}
\hline No & Profil Kognitif & Definisi \\
\hline & & $\begin{array}{l}\text { dari informasi yang } \\
\text { disajikan. }\end{array}$ \\
6 & Membandingkan & $\begin{array}{l}\text { Mencari hubungan } \\
\text { antara dua ide, objek } \\
\text { atau hal-hal serupa. }\end{array}$ \\
7 & menjelaskan & $\begin{array}{l}\text { Mengkontruksi } \\
\text { model sebab akibat } \\
\text { dari suatu sistem }\end{array}$ \\
\hline
\end{tabular}

Dalam pembelajaran fisika dasar mahasiswa menemukan banyak kesulitan dalam memahami dan menganalisis materi. Kesulitan ini disebabkan analisis fisika dasar melibatkan kalkulus dasar(Nguyen \& Rebello, 2011). Hal ini menyebabkan pemahaman, analisis serta hasil belajar mahasiswa rendah.

Permasalahan yang terjadi dalam pembelajaran adalah bagaimana mewujudkan atau mengimplementasikan proses - proses kognitif agar dicapai level kognitif yang memadai. Hilir dari pencapaian dari proses kognitif tersebut dapat dilihat dari hasil belajar siswa.

Hal inilah yang menjadi urgensi penelitian ini yakni penggunaan model blended learning dapat meningkatkan level kognitif siswa melalui keaktifannya.

Berdasarkan Latar belakang tersebut yang menjadi rumusan permasalahan dari penelitian ini adalah apakah metode blended learning dengan pendekatan kalkulus dasar dapat meningkatkan hasil belajar mahasiswa.

\section{METODE PENELITIAN}

Sampel dari penelitian ini adalah tiga puluh lima mahasiswa jurusan tambang ISTP TA 2020/2021 yang dijadikan satu grup Sampel. Penelitian ini dilakukan pada masa Pandemi Covid-19 dimana pihak Universitas melakukan kebijakan protocol kesehatan kepada mahasiswa Institut Sains dan Teknologi TD Pardede Medan. Waktu penelitian ini dilakukan selama satu semester yakni semester ganjil. 
Pada penelitian ini metode yang digunakan adalah metode Quasi Ekperimen dengan teknik pretest dan posttest one group design. Hasil belajar yang ingin di teliti pada penelitian ini adalah hasil dari analisis profil proses kognitif pemahaman konsep yang dihasilkan melalui metode blended learning dengan pendekatan kalkulus dasar.

Tabel 2. Interpretasi Indeks Gain

\begin{tabular}{cc}
\hline Skor gain & interpretasi \\
\hline $\mathrm{g} \geq 0,7$ & Tinggi \\
$0,3 \leq \mathrm{g}<0,7$ & Sedang
\end{tabular}

\begin{tabular}{cc}
\hline Skor gain & interpretasi \\
\hline $\mathrm{g}<0,3$ & Rendah
\end{tabular}

Teknik dalam menganalisa data pretest dan posttest adalah analisa nilai gain (Gain Score). Analisa nilai gain ini untuk menghitung peningkatan score dari posttest. Level peningkatan hasil belajar berupa gain ditunjukkan dalam tabel 2 (interpretasi indeks gain). Persamaan (1) merupakan rumus untuk menghitung nilai gain.

$N$ gain $=\frac{\text { Skor } \text { Posttest }- \text { Skor } \text { Pretest }}{\text { Skor Ideal }- \text { Skor Pretest }}$

Tabel 3. Peningkatan Nilai Profil Kognitif

\begin{tabular}{llcc}
\hline No & Profil Kognitif & \multicolumn{2}{c}{ Rata - Rata Nilai } \\
\cline { 3 - 4 } & & Konvensional & Blended Learning \\
\hline 1 & Interpretasi, & 30,45 & 78,56 \\
2 & Mencontohkan, & 40,11 & 80,43 \\
3 & Mengklasifikasikan, & 35,34 & 88,34 \\
4 & Menggeneralisasi & 37,34 & 79.56 \\
5 & Inferensi & 29,97 & 78,99 \\
6 & Membandingkan & 32,56 & 79,45 \\
7 & menjelaskan & 37,77 & 82,76 \\
\hline
\end{tabular}

\section{HASIL DAN PEMBAHASAN}

Data atau informasi yang didapat dalam penelitian ini berupa data yang diambil dari lapangan dimana data tersebut menunjukkan sebagai akibat metode blended learning dengan pendekatan kalkulus dasar.

\section{Hasil}

Data hasil penelitian berupa data peningkatan profil proses pemahaman konsep dan hasil belajar mahasiswa. Profil proses pemahaman konsep terdiri dari Interpretasi, Mencontohkan, Mengklasifikasikan, Menggeneralisasi, Inferensi, Membandingkan dan menjelaskan. Ketercapaian dari profil tersebut dilihat dari presisi jawaban yang ditampilkan. Rata- rata nilai didapat dengan menjumlahkan semua nilai peserta test untuk tiap-tiap profil Kognitif pada model konvensional dan model blended learning.

Tabel 3 berisikan data peningkatan profil proses pemahaman konsep melalui dua perlakuan yakni metode konvensional dan metode blended learning.Hasil belajar merupakan hasil test ujian berupa soal materi konsep yang diberikan setelah proses pembelajaran diberikan.

Materi yang diujikan adalah hantaran kalor, termodinamika dan listrik magnet. Hasil belajar merupakan pretest dan posttest terhadap mahasiswa. Pretest merupakan pengujian terhadap metode konvensional dan posttest merupakan pengujian terhadap hasil blended learning. Rata- rata nilai didapat dengan menjumlahkan semua nilai peserta test untuk tiap-tiap profil Kognitif 
pada model konvensional dan model blended learning.
Tabel 4 merupakan hasil belajar yang dihasilkan mahasiswa terhadap tiga materi yang diujikan.

Tabel 4. Nilai Hasil Belajar

\begin{tabular}{cccccc}
\hline No & Materi & \multicolumn{2}{c}{ Rata - Rata Nilai } & Uji & Kategori \\
\cline { 3 - 4 } & Konvensional & $\begin{array}{c}\text { Blended } \\
\text { Gearning }\end{array}$ & \\
\hline 1 & Hantaran Kalor & 24 & 75 & 0.6 & Sedang \\
2 & Termodinamika & 23 & 76 & 0.6 & Sedang \\
3 & Listrik Magnet & 27 & 81 & 0.7 & Tinggi \\
\hline
\end{tabular}

\section{Pembahasan}

Pembelajaran model blended learning adalah pembelajaran yang mengkontruksi keaktifan siswa. Pembelajaran ini menggabungkan pembelajaran konvensional dengan e-learning dimana siswa didorong dalam penggunaan media elektronik sebagai sumber media. Siswa didorong untuk menggali informasi lebih banyak dengan melakukan observasi yang akan dapat meningkatkan pemahaman konsep sehingga meningkatkan hasil belajar, (Hayati et al., 2017).

Pada penelitian ini model pembelajaran yang digunakan adalah model blended learning dengan pendekatan kalkulus dasar. Pada tahap implementasi blended learning materi fisika dasar dianalisis melalui tekni kalkulus dasar untuk menguraikan konsep dan permasalahan yang akan dicari solusinya. Teknik diferensial berguna untuk menganalisis perubahan besaran fisis yang ektrim dan integral berguna untuk menjumlahkan seluruh atau sebahagian kuantitas fisis dengan batasan yang diberikan.

Pada model pembelajaran ini materi yang diberikan berupa Hantaran Kalor, termodinamika dan listrik magnet. Dari data hasil penelitian diperoleh nilai rata-rata keseluruhan aspek interpretasi secara model konvensional yakni sebesar 30,45 dan secara model blended learning 78,56. Hal ini menunjukkan ada pingkatan pemahaman dalam mengubah bentuk - bentuk formula fisis terhadap suatu masalah fisis. Dari data hasil penelitian diperoleh nilai rata-rata keseluruhan aspek mencontohkan secara model konvensional yakni sebesar 40,11 dan secara model blended learning 80,43. Hal ini menunjukkan ada peningkatan pengetahuan dalam mencontohkan kasus kasus khusus masalah fisis. Dari data hasil penelitian diperoleh nilai rata-rata keseluruhan aspek mengklasifikasikan secara model konvensional yakni sebesar 35,34 dan secara model blended learning 88,34. Hal ini menunjukkan ada peningkatan wawasan dalam pengklasifikasian jenis jenis masalah yang terbatas dalam kategori tertentu. Dari data hasil penelitian diperoleh nilai rata-rata keseluruhan aspek menggeneralisasi secara model konvensional yakni sebesar 37,34 dan secara model blended learning 79,56. Hal ini menunjukkan ada peningkatan penguasaan konsep yang lebih umum dengan menggeneralisasikan formula- formula fisis. Dari data hasil penelitian diperoleh nilai rata-rata keseluruhan aspek inferensi secara model konvensional yakni sebesar 29,97 dan secara model blended learning 78,99. Hal ini menunjukkan ada peningkatan penguasaan dalam menarik kesimpulan yang logis dari konsep awal. Dari data hasil penelitian diperoleh nilai rata-rata keseluruhan aspek membandingkan secara model konvensional yakni sebesar 32,56 dan secara model blended learning 79,45 Hal ini menunjukkan ada peningkatan dalam membandingkan dua objek yang berbeda atau sama. Dari data 
hasil penelitian diperoleh nilai rata-rata keseluruhan aspek menjelasakan secara model konvensional yakni sebesar 37,77 dan secara model blended learning 82,76 . Hal ini menunjukkan ada peningkatan pemahaman akan sebab akibat dari konsep fisis.

Penilaian hasil belajar pengaruh model blended learning di peroleh dengan memberikan soal tes hasil belajar kepada mahasiswa tiap-tiap materi fisika dasar dengan pendekatan kalkulus dasar. Denagn model tes essay mahasiswa diharuskan menjawab tes dengan uraian lengkap agar dapat dinilai proses - proses kognitif yang terjadi. Penilaian peningkatan hasil belajar diukur dari uji gain tiap - tiap materi yang diujikan. Dari data hasil penelitian diperoleh nilai rata-rata hasil belajar pada materi hantaran kalor secara model konvensional yakni sebesar 24 dan secara model blended learning 75 dengan uji gain sebesar 0,6 Hal ini menunjukkan ada peningkatan hasil belajar pada materi hantaran kalor. Dari data hasil penelitian diperoleh nilai rata-rata hasil belajar pada materi termodinamika secara model konvensional yakni sebesar 23 dan secara model blended learning 76 dengan uji gain sebesar 0,6 . Hal ini menunjukkan ada peningkatan hasil belajar pada mater termodinamika. Dari data hasil penelitian diperoleh nilai rata-rata hasil belajar pada materi listrik magnet secara model konvensional yakni sebesar 27 dan secara model blended learning 81 dengan uji gain sebesar 0,7. Hal ini menunjukkan ada peningkatan hasil belajar pada materi listrik magnet. Hasil dari keseluruhan tes menunjukkan bahwa terdapat peningkatan hasil belajar tiap - tiap pertemuan.

Pendekatan Kalkulus dasar merupakan pendekatan yang sangat tepat pada pembelajaran fisika dasar. Penelitian sebelumnya (Haryadi R, 2015) telah menguatkan bahwa penggunaan konsep kalkulus dasar (diferensial dan integral ) dapat meningkatkan penguasaan konsep fisika dasar. Dasar dari hubungan kalkulus dasar dengan fisika dasar adalah terdapatnya kesamaan analisis kognitif (kajian ilmu) diantara keduanya. Fisika dasar yang menjabarkan permasalahan keadaan fisis pada level miskroskopik dan makroskopik dapat diterangkan dengan bahasa kalkulus dasar berupa diferensial dan integral.Integrasi diferensial digunakan dalam banyak pengantaar Masalah fisika dan untuk solusi yang lebih luas. Mengembangkan keahlian untuk menggunakan kalkulus dasar dalam fisika diperlukan Menyiapkan integral dalam masalah fisika bisa jadi dibagi menjadi beberapa langkah: menyiapkan ekspresi untuk kuantitas yang sangat kecil (misalnya, $\mathrm{dE}, \mathrm{dB}$ ), mengumpulkan jumlah yang sangat kecil, menentukan variabel integrasi, dan mengubah integral menjadi bentuk yang bias dievaluasi secara matematis. Sebagai contoh $\mathrm{E}=\mathrm{k} \frac{\mathrm{q}}{\mathrm{r}^{2}}$ menjadi $\mathrm{dE}=\mathrm{k} \frac{\mathrm{dq}}{\mathrm{r}^{2}}$ yang akan diintegralkan untuk mendapatkan solusi. Beberapa istilah digunakan seperti matematika menjadi alat (tool) untuk dapat memecahkan persoalan-persoalan fisika, karena pada kenyataannya memang fisika tidak terlepas dari perhitungan matematis seperti menjumlah, mengurangi, mengalikan, mendeferensialkan, mengintegralkan dan lain-lain. Sebagai contoh untuk memperdalam pemahaman konsep kinematika dibutuhkan keterampilan matematis guna mencari besaran-besaran fisisnya yaitu dengan diferensial dan integral (Haryadi, 2015). Quale (2011) mengatakan bahwa untuk merepresentasikan hukumhukum ilmiah yang digunakan dan penyelidikan konsekuensi hukum-hukum dalam fisika dan berbagai cabang ilmunya, sangat dibutuhkan formulasi matematika sehingga hubungan antara matematika dan fisika tidak dapat dipisahkan. Oleh karena itu, untuk dapat menguasai ilmu fisika maka 
harus bisa menguasai ilmu matematika terlebih dahulu supaya persoalan yang terdapat dalam konten fisika dapat diselesaikan dengan mudah. Fisika merupakan bagian dari ilmu sains yang memiliki korelasi dengan matematika. Maka dari itu korelasi antara Kalkulus dan fisika dasar adalah suatu kenyataan yang menunjukkan keeratan hubungan dua variabel penelitian ilmiah

\section{PENUTUP}

Dari data hasil penelitian adan peningkatan peningkatan penguasaan, pemahaman maupun analisis profil kognitif mahasiswa setelah menggunakan model blended learning dengan pendekatan kalkulus dasar. Adanya peningkatan uji gain pada tiap tiap pertemuan yakni pertemuan pertama sebesar nol koma enam, pertemuan kedua nol koma enam dan pertemuan ketiga nol koma tujuh maka dapat disimpulkan ada peningkatan hasil belajar mahasiswa setelah menggunakan model blended learning dengan pendekatan kalkulus dasar. Peningkatan ini terjadi karena model blended learning memberikan kesempatan belajar yang lebih lama dan sumber ilmu yang lebih beragam. Keaktifan mahasiswa dapat ditingkatkan dalam model pembelajaran ini.

Model pembelajaran blended Learning serta pendekatan kalkulus dasar adalah suatu kolaborasi yang dapat meningkatkan keaftifan, pemahaman seta analisis konsep fisika, maka dari itu saran penulis perlu dikembangkan suatu buku penuntun yang dapat dipakai sebagai rujukan kepada mahasiswa.

\section{UCAPAN TERIMA KASIH}

Dalam kesempatan ini saya menyampaikan banyak terimah kasih kepada bapak dekan fakultas teknologi dan mineral yang mengizinkan saya untuk melakukan penelitian ini serta kepada staf LPPM yang memfasilitasi penelitian saya.

\section{REFERENSI}

Anwar Mutaqin, Indiana Marethi, dan Syamsuri (2016). Model Blended Learning Di Program Studi Pendidikan Matematika UNIRTA. Cakrawala Pendidikan, Februari 2016, Th. XXXV, No. 1

Haryadi R (2015). Urgensi Matematika Dalam Memahami Konsep Kinematika. Jurnal Pengabdian dan Pemberdayaan Masyarakat (JPPM), 9(1).

Hayati, S. N., Hikmawati, H., \& Wahyudi, W. (2017). Pengaruh model pembelajaran inkuiri dengan menggunakan media simulasi terhadap hasil belajar fisika siswa kelas X MIA SMAN 1 Lingsar Lombok Barat Tahun Pelajaran 2016/2017. Jurnal Pendidikan Fisika dan Teknologi, 3(1), 48-54.

Hidayatullah, Z., Makhrus, M., \& Gunada, I. W. (2018). Analisis Tingkat Kemampuan Berpikir Kritis Gelombang Mekanik Melalui Pembelajaran Dengan Pendekatan Konflik Kognitif. Jurnal Pendidikan Fisika dan Teknologi, 4(2), 151-157.

Konopka, C. L. (2015), Active Teaching And Learning Methodologies. Some Considerations. Scientific Research Publishing Inc.

Nisrina, N., Gunawan, G., \& Harjono, A. (2017). Pembelajaran kooperatif dengan media virtual untuk peningkatan penguasaan konsep fluida statis siswa. Jurnal Pendidikan Fisika dan Teknologi, 2(2), 66-72.

Quale, A. (2011). On the role of mathematics in physics. Science \& Education, 20(3), 359-372. 